SISTEMA
ELETRONIICO
DE REVISTAS
SER I UfPR

\title{
A (des)proteção do solo em Goiás: um estudo de caso da microrregião de Quirinópolis - GO
}

\section{The soil (un)protection in Goiás: a case study of the Quirinópolis microregion - GO}

\author{
Jéssica Dafico Moreira da Costa Gomes REIS ${ }^{1 *}$, Adriana Aparecida SILVA ${ }^{1}$, Josana de Castro PEIXOTO ${ }^{1}$ \\ ${ }^{1}$ Universidade Estadual de Goiás (UEG), Anápolis, GO, Brasil. \\ *E-mail de contato: jessica_gomes18@hotmail.com
}

Artigo recebido em 11 de março de 2019, versão final aceita em 14 de outubro de 2019.

RESUMO: $\quad$ A partir da década de 70 se inicia no estado de Goiás um processo de intensificação da expansão da fronteira agrícola estimulada por políticas governamentais. A entrada da cana-de-açúcar no estado se relaciona às condições geoambientais favoráveis para o seu cultivo, destacando-se a mesorregião sul de Goiás como a mais importante região produtora do estado na qual está inserida, dentre outras, a microrregião de Quirinópolis. Diante desse cenário, o presente artigo buscou analisar a discrepância entre o uso da terra e capacidade de uso dessa região no período entre 2004 e 2010, contrapondo o resultado obtido à legislação vigente à época analisada. A realização deste estudo, comparando os dados apurados antes e depois da entrada da cana-deaçúcar, permitiu identificar a abrupta expansão da cana e a inaptidão do solo da microrregião para o cultivo dessa cultura, especialmente em razão da utilização de processos altamente tecnificados, os quais resultam em previsíveis impactos ambientais. Ao se analisar esses resultados em paralelo à legislação vigente à época, pode-se perceber o descompasso entre a previsão legal e a efetiva proteção do solo, principalmente em razão da ausência de leis específicas voltadas para a proteção desse recurso natural e da maneira rasa como o solo é considerado nas demais leis estudadas.

Palavras-chave: solos; uso intensivo; legislação; impactos ambientais.

ABSTRACT: From the 1970s, it starts in the state of Goiás an intensification process of the agricultural frontier expansion stimulated by government policies. The entrance of sugarcane in the state is related to favorable geoenvironmental conditions for its cultivation, highlighting the southern mesoregion of Goiás as the most important producing region of the state, in which is inserted, among others, the Quirinópolis microregion. Within this context, this article sought to analyze the discrepancy between land use and land use capacity in this region between 2004 and 2010, contrasting the result obtained with the legislation in force at the 
time analyzed. The realization of this study, comparing the data before and after the entrance of sugarcane allowed to identify the abrupt expansion of sugarcane and the inadequacy of the soil of the microregion for this cultivation, especially due to the use of high technified processes that result in predictable environmental impacts. When analyzing these results in parallel with the legislation in force at the time, it is possible to perceive the mismatch between legal forecast and the effective protection of the soil, mainly due to the absence of specific laws aimed at the protection of this natural resource and the shallow way that the soil is considered in the other laws studied.

Keywords: soil; intensive use; legislation; environmental impacts.

\section{Introdução}

A ocupação do estado de Goiás durante o século XX apresentou formas diversas de uso da terra, porém, com uma característica prevalente: a relação com a agricultura e a pecuária. Essa ocupação se intensificou a partir da década de 70 por meio da expansão da fronteira agrícola no estado, a qual foi estimulada por políticas governamentais vigentes à época, como o II Plano Nacional de Desenvolvimento, que perdurou de 1975 a 1979, e o Programa de Desenvolvimento dos Cerrados - POLOCENTRO, criado por meio do Decreto $\mathrm{n}^{\circ} 75.320$ de 29 de janeiro de 1975 e considerado o programa de maior importância para o desenvolvimento goiano (Rocha \& Maciel, 2013).

Em 1979, com o fim do POLOCENTRO, iniciou-se a implantação do PRODECER - Programa Nipo-Brasileiro de Desenvolvimento Agrícola da Região dos Cerrados, fruto de uma parceria firmada entre o Brasil e o Japão com o intuito de explorar as terras do Cerrado. Tal programa buscou promover ocupação e fomento da produção agrícola, sob a justificativa de existência de um vasto espaço inexplorado (Pessôa \& Inocêncio, 2014).

Em um primeiro momento, o modo de ocupação das terras goianas se deu por meio da conversão da vegetação natural em pastagens, seguida de uma nova conversão voltada para a agricultura de grãos como milho e soja. Com o Programa Nacional do Álcool - Próalcool, entre 1975 e 1990, veio a cana-de-açúcar, por meio de subsídios do governo voltados ao incentivo da produção energética, isso diante da crise internacional do petróleo em 1973 (Silva \& Miziara, 2011).

Porém, entre a segunda metade da década de 1980 e a primeira metade da década de 1990, houve uma estagnação do avanço da cana no estado de Goiás em consequência de falhas no Próalcool que levaram à crise sucroalcooleira e ao descrédito no programa. Esse cenário somente mudou no início do século XXI com o surgimento dos automóveis com motores movidos à gasolina e álcool em 2003, chamados de "flex fuel", fomentando uma maior demanda pelo álcool, o que refletiu diretamente na necessidade de ampliação da produção sucroalcooleira e instalação de novas usinas em Goiás (Miziara, 2009).

Goiás apresenta condições edafoclimáticas (Manzatto et al., 2009) e pedogeomorfológicas (Castro et al., 2007) favoráveis para o cultivo da cana-de-açúcar, além de vantagens logísticas para o escoamento da produção (Silva \& Miziara, 2011), o que certamente favoreceu a entrada dessa cultura. 
Dentre as principais regiões produtoras, a mesorregião sul de Goiás é considerada a mais importante, destacando-se dentro desta a microrregião de Quirinópolis, juntamente com a do Rio Meia Ponte e Rio dos Bois (Castro et al., 2010).

Na microrregião de Quirinópolis, percebe-se que até 2004 o uso da terra era 100\% destinado a usos diversos ao plantio de cana-de-açúcar, tendo como marco inicial do ingresso dessa monocultura o ano de 2006. Em 2010, por sua vez, a região já apresentava o índice de 7,23\% do uso da terra ocupado pelo cultivo da cana, o que correspondia a 116.003,007 ha, demonstrando a acelerada expansão açucareira nesse curto período (Silva \& Castro, 2011).

Essa abrupta entrada da cana-de-açúcar nessa microrregião foi marcada pela substituição de culturas anuais e pastagem, trazendo consigo consequências socioambientais e econômicas, inexistindo a implantação de medidas preventivas com relação às externalidades negativas. Foram desconsiderados, inclusive, os impactos ambientais já conhecidos, conforme destacam Castro et al. (2010, p. 189),

Os impactos diretos mais considerados são a competição por terras agrícolas, o risco de novos desmatamentos, além de poluição do ar (queimadas, emissões), contaminação dos solos e águas, problemas decorrentes tanto do manejo agrícola como do processo industrial. Os impactos indiretos derivam das práticas agrícolas em áreas de pecuária e não são muito diferentes destes. Mas, embora o deslocamento de culturas anuais para áreas antes ocupadas por pastagens não seja fenômeno novo na expansão da fronteira agrícola no Brasil, neste caso pode estar ocorrendo o deslocamento em direção às áreas com maiores riscos para essa prática por causa de sua menor aptidão, podendo causar impactos ambientais mais sérios. [...]
Para a preservação ambiental de matrizes como o solo e os recursos hídricos, faz-se fundamental que as atividades agrícolas sejam realizadas em atenção à capacidade de uso da terra da região onde se pretende explorar (Lepsch et al., 1991). O uso inadequado da terra, em desconformidade com sua capacidade, acarreta danos diretos e indiretos aos recursos naturais, tendo como consequência a degradação ambiental (Pereira et al., 2006).

A degradação ambiental é definida pela Política Nacional do Meio Ambiente - Lei n ${ }^{\circ}$ 6.938/1981 (Brasil,1981) como "a alteração adversa das características do meio ambiente". Assim, o uso inadequado dos recursos naturais está perfeitamente englobado nesse conceito. Isso porque o reflexo da negligência da observância da capacidade do uso da terra resulta na alteração das características naturais dos recursos, acarretando, por exemplo, a erosão e compactação do solo em regiões de plantio de cana.

Notadamente, a pesquisa e a ciência têm se voltado para a necessidade de se estudar o meio ambiente de uma maneira interdisciplinar, por meio da desconcentração do conhecimento e integração das áreas dos saberes. Dessa forma, busca-se promover uma análise ampla, favorecendo a inter-relação dos fatores e agentes envolvidos na temática ambiental (Sartori, 2005 apud Capra, 1982).

Uma análise que contemple a visão interdisciplinar é possível através da Teoria Geral do Sistema (TGS), a qual defende a educação integrada como fonte para se desenvolver um estudo pautado na comunicação das ciências naturais e sociais, opondo-se à visão reducionista dos saberes (Sartori, 2005 apud Bertalanffy, 1973). A TGS nos aponta para a visão holística do ambiente, o qual é constituído por várias frações interdependentes entre si. Ocorre que, ao se analisar a legislação nacional brasileira, 
percebemos facilmente a ausência de comunicação das leis promulgadas com os estudos desenvolvidos por profissionais de outras áreas dos saberes, o que acarreta a fragilidade tanto da legislação propriamente dita quanto dos direitos que se visa preservar por meio destas.

Considerando o cenário nacional em termos de proteção ambiental, identifica-se uma precariedade em estudos interdisciplinares prévios à propositura de projetos de lei. Tal situação é plenamente perceptível quando da análise específica das leis que regulam o uso dos recursos naturais brasileiros, estas muitas vezes em descompasso com a real necessidade e efetividade da preservação ambiental (Ab'saber, 2010).

Diante disso, busca-se por meio deste estudo trazer uma abordagem acerca da proteção jurídica, ou ausência desta, quanto ao recurso natural solo, o qual é indispensável para o processo produtivo e a preservação da biodiversidade. Para tanto, o trabalho terá como referência o estudo desenvolvido por Silva \& Castro (2011), que trata do processo de expansão da cana-de-açúcar na microrregião de Quirinópolis - GO, no período entre 2004 e 2010, contrapondo o resultado do uso efetivo da terra à legislação vigente à época analisada.

\section{A legislação ambiental brasileira e o recurso solo}

No que tange ao solo, a Constituição Federal, em seu artigo 24, inciso VI, estabelece como competência concorrente da União, dos estados e dos municípios legislar sobre a proteção ao solo e aos recursos naturais. Tratando-se de competência concorrente, a União se limita a legislar sobre nor- mas gerais acerca da temática, cabendo aos estados e municípios exercerem a chamada competência suplementar, legislando sobre questões específicas, isso em atenção as peculiaridades de cada região.
Art. 24. Compete à União, aos Estados e ao Distrito Federal legislar concorrentemente sobre:
(...)
VI - florestas, caça, pesca, fauna, conservação da na- tureza, defesa do solo e dos recursos naturais, proteção do meio ambiente e controle da poluição;
(...)
$\S 3^{\circ}$ Inexistindo lei federal sobre normas gerais, os Estados exercerão a competência legislativa plena, para atender a suas peculiaridades (Brasil, 1988).

Considerando estritamente o recurso ambiental solo, objeto deste estudo, percebe-se que não há uma lei federal própria que estabeleça regras gerais, conceitos e padrões norteadores para o uso do solo e a proteção deste. O que se tem, em verdade, são textos legais esparsos versando sobre a proteção ambiental, sendo que pouco se faz menção ao solo como recurso natural e, quando se faz, o tema é tratado de maneira rasa e ausente de determinação pontual quanto aos limites e formas de uso.

A principal lei federal a ser considerada quando se trata de uso do solo é a chamada Lei de Política Agrícola (Lei no 8.171/1991), a qual estabelece princípios e normas a serem seguidas no desenvolvimento das atividades agropecuárias. Nesta, ao longo de seus 108 artigos, o solo aparece apenas 5 (cinco) vezes, sendo que, em todos os trechos legais, limita-se a determinar o controle do uso do solo e suposto incentivo à conservação deste. Tal lei se restringe a tratar das funções administrativas do Estado, sem estabelecer formas e limites para o uso da terra ou sanções em caso de evidente degradação, como podemos ver a seguir:

Art. 19. O Poder Público deverá: 


\section{(...)}

II - disciplinar e fiscalizar o uso racional do solo, da água, da fauna e da flora;

\section{(...)}

Art. 30. O Ministério da Agricultura e Reforma Agrária (MARA), integrado com os Estados, o Distrito Federal, os Territórios e os Municípios, manterá um sistema de informação agrícola ampla para divulgação de:

(...)

$\mathrm{V}$ - cadastro, cartografia e solo das propriedades rurais (...)

Art. 48. O crédito rural, instrumento de financiamento da atividade rural, será suprido por todos os agentes financeiros sem discriminação entre eles, mediante aplicação compulsória, recursos próprios livres, dotações das operações oficiais de crédito, fundos e quaisquer outros recursos, com os seguintes objetivos: (...)

III - incentivar a introdução de métodos racionais no sistema de produção, visando ao aumento da produtividade, à melhoria do padrão de vida das populações rurais e à adequada conservação do solo e preservação do meio ambiente;

Art. 96. Compete ao Poder Público implementar um conjunto de ações no âmbito da mecanização agrícola, para que, com recursos humanos, materiais e financeiros, alcance:

(...)

VI - divulgar e estimular as práticas de mecanização que promovam a conservação do solo e do meio ambiente.

(...)

Art. 97. No prazo de noventa dias da promulgação desta lei, o Poder Executivo encaminhará ao Congresso Nacional projeto de lei dispondo sobre: produção, comercialização e uso de produtos biológicos de uso em imunologia e de uso veterinário, corretivos, fertilizantes e inoculantes, sementes e mudas, alimentos de origem animal e vegetal, código e uso de solo e da água, e reformulando a legislação que regula as atividades dos armazéns gerais.

Art. 102. O solo deve ser respeitado como patrimônio natural do País.

Parágrafo único. A erosão dos solos deve ser comba- tida pelo Poder Público e pelos proprietários rurais (Brasil, 1991).

Percebe-se, então, a fragilidade com que o recurso ambiental solo é tratado em âmbito federal, identificando, inclusive, uma dissonância entre o que se estabelece em lei e a sua real aplicabilidade. Vê-se que o artigo 102 supracitado assegura ser o solo considerado um "patrimônio nacional" e, por isso, deve ser conservado, porém, na prática, sequer leis específicas são dedicadas a esse recurso. Curiosamente, decretou-se no Brasil, no dia 13 de novembro de 1989 , a Lei ${ }^{\circ} 7.876$, a qual institui o "dia nacional da conservação do solo", devendo este ser comemorado no dia 15 de abril, porém, como dito, inexiste qualquer lei federal que verse exclusivamente sobre a proteção do solo (Brasil, 1989)

Em termos de criminalização de condutas que resultem na degradação do solo, a lei de crimes ambientais (Lei no 9.605/1998) não tipifica como crime qualquer ato no sentido de violação ao uso inadequado da terra quando do desenvolvimento de atividades agrícolas ou retirada da vegetação. O solo somente é mencionado em duas circunstâncias: a primeira como uma condição de aumento de pena, quando o uso for considerado criminoso e acarretar na instalação de processos de erosão do solo; e a segunda tipificando como crime a construção em solo não edificável, o que está mais relacionado à questão urbanista do que agrária ou de conservação do recurso (Brasil, 1998).

Deve-se destacar, ainda, o Código Florestal Brasileiro vigente (Lei $\left.n^{\circ} 12.651 / 2012\right)$ como uma das legislações que perpassam pela matéria de proteção aos recursos naturais, porém, como as demais leis ambientais federais, não há uma redação robusta visando resguardar e tutelar efetivamente o uso do 
solo. Pode-se verificar a superficialidade da abordagem e regulamentação da proteção desse recurso natural por meio da leitura de trechos específicos da legislação florestal:

Art. 1-A. Esta Lei estabelece normas gerais sobre a proteção da vegetação, áreas de Preservação Permanente e as áreas de Reserva Legal; a exploração florestal, o suprimento de matéria-prima florestal, o controle da origem dos produtos florestais e o controle e prevenção dos incêndios florestais, e prevê instrumentos econômicos e financeiros para o alcance de seus objetivos.

(...)

I - afirmação do compromisso soberano do Brasil com a preservação das suas florestas e demais formas de vegetação nativa, bem como da biodiversidade, do solo, dos recursos hídricos e da integridade do sistema climático, para o bem estar das gerações presentes e futuras;

(...)

III - ação governamental de proteção e uso sustentável de florestas, consagrando o compromisso do País com a compatibilização e harmonização entre o uso produtivo da terra e a preservação da água, do solo e da vegetação;

(...)

$\mathrm{V}$ - fomento à pesquisa científica e tecnológica na busca da inovação para o uso sustentável do solo e da água, a recuperação e a preservação das florestas e demais formas de vegetação nativa;

(...)

Art. 3 Para os efeitos desta Lei, entende-se por:

(...)

VI - uso alternativo do solo: substituição de vegetação nativa e formações sucessoras por outras coberturas do solo, como atividades agropecuárias, industriais, de geração e transmissão de energia, de mineração e de transporte, assentamentos urbanos ou outras formas de ocupação humana;

(...)

Art. 26. A supressão de vegetação nativa para uso alternativo do solo, tanto de domínio público como de domínio privado, dependerá do cadastramento do imóvel no CAR, de que trata o art. 29, e de prévia autorização do órgão estadual competente do Sisnama (Brasil, 2012).

Muito embora a Lei $n^{\circ} 12.651 / 2012$ seja a legislação vigente, seguindo o princípio tempus regit actum - o tempo rege o ato, que preceitua que os casos concretos devem ser analisados e julgados com base na lei vigente à época, devemos considerar a redação do revogado Código Florestal (Lei n ${ }^{\circ}$ 4.771/1965) para análise do período de 2004 a 2010, já que o atual código entrou em vigor em 2012.

Nesse sentido, analisando a Lei $n^{\circ} 4.771 / 1965$, não obstante a inexistência de capítulo específico que trata sobre a conservação do solo, percebe-se nesta a preocupação do legislador com esse recurso. No artigo 37 - A, inserido nessa lei em 2001 por meio da Medida Provisória $n^{0}$ 2.166-67, a qual também foi revogada pelo Novo Código Florestal (Lei $\left.\mathrm{n}^{\circ} 12.651 / 2012\right)$, há destaque para a preocupação com o respeito à capacidade de uso do solo determinando que

\begin{abstract}
Não é permitida a conversão de florestas ou outra forma de vegetação nativa para uso alternativo do solo na propriedade rural que possui área desmatada, quando for verificado que a referida área encontra-se abandonada, subutilizada ou utilizada de forma inadequada, segundo a vocação e capacidade de suporte do solo (Brasil,1965).
\end{abstract}

Dessa forma, vê-se claramente a vedação legal à retirada da vegetação nativa para o desenvolvimento de qualquer que seja a atividade agropecuária, quando a propriedade possuir área desmatada e for identificada discrepância entre o uso e a capacidade de uso da terra. Muito embora a redação deste artigo utilize como parâmetro o conceito de 
capacidade de uso da terra e a análise do seu uso efetivo, percebe-se que o cerne da imposição legal se encontra na proteção da vegetação nativa e não diretamente na proteção do solo.

Nesse sentido, ao utilizar como referência a retirada de vegetação nativa, desconsidera-se as áreas antropizadas quando da análise da proteção do solo. Ou seja, em situações em que já existia atividade agropecuária compatível com capacidade da terra e, converte-se o tipo de uso para, por exemplo, o cultivo da cana-de-açúcar, como é o objeto deste estudo, nos termos da Lei no $4.771 / 1965$, não há ilegalidade, assim como não resguarda o solo quanto aos impactos inerentes à entrada dessa nova forma de uso.

Uma vez demonstrada a ineficiência protetiva por parte da legislação federal, tratando-se de competência suplementar, caberia ao estado de Goiás a promulgação de leis específicas acerca da proteção do solo da região. Seguindo o mesmo critério acerca da legislação vigente no recorte temporal considerado neste estudo, utilizaremos o Código Floresta do Estado de Goiás de 1995 (Lei no 12.596/1995), muito embora essa lei tenha sido revogada em 2013 por meio da promulgação da Lei $n^{\circ}$ 18.104/2013 (Goiás, 2013).

Ocorre que, ao se analisar o teor da lei $\mathrm{n}^{\circ}$ 12.596/1995, podemos observar que esta também não assegura a devida tutela do solo, ao contrário, faz menção à autorização para retirada de vegetação para uso alternativo do solo, se considerado que tal ação não implique na instalação de processos de degradação ambiental. No entanto, é sabido que inexiste a possibilidade de supressão desconexa à degradação, isso porque é consenso entre os pesquisadores que a retirada da vegetação nativa expõe o solo a diversos impactos, tais como: erosão, compactação, empobrecimento, salinização e perda de biodiversidade (Bertoni \& Lombardi Neto, 2005; Freire, 2006; Resende, et al., 2007; Santos et al., 2012). Eis o que reza a lei estadual:

Art. 30 - As autorizações para desmatamento através de corte raso, para uso alternativo do solo em áreas de grande relevância ambiental, a juízo do órgão de controle ambiental competente, ou superiores a 500 ha (quinhentos hectares), em qualquer local do Estado, somente poderão ser concedidas depois de apresentados e aprovados tanto o estudo de Impacto Ambiental quanto o respectivo Relatório de Impacto Ambiental - RIMA, elaborado conforme dispuser o regulamento dessa lei (Goiás, art. 30, 1995).

Este estudo deverá ser apresentado à Secretaria de Estado de Meio Ambiente, Recurso Hídricos, Infraestrutura, Cidades e Assuntos Metropolitanos - SECIMA, órgão público competente responsável pela fiscalização e controle de questões ambientais no estado (Goiás, 1989). Percebe-se, no entanto, que a obrigação imposta pela legislação estadual, em verdade, tem origem constitucional, ou seja, está inserida na Constituição Federal em seu art. 225, inciso IV, que estabelece a obrigatoriedade de apresentação de estudo de impactos ambientais (Brasil, 1988).

Art. 225. Todos têm direito ao meio ambiente ecologicamente equilibrado, bem de uso comum do povo e essencial à sadia qualidade de vida, impondo-se ao Poder Público e à coletividade o dever de defendê-lo e preservá- lo para as presentes e futuras gerações.

(...)

IV - exigir, na forma da lei, para instalação de obra ou atividade potencialmente causadora de significativa degradação do meio ambiente, estudo prévio de impacto ambiental, a que se dará publicidade (Brasil, 1988). 
Considerando o desenvolvimento da atividade sucroalcooleira, além das regras gerais relativas à permissão de retirada da vegetação nativa, exigia-se uma cautela especial, por se tratar de uma atividade potencialmente causadora de degradação ambiental e em crescente expansão. Diante disso, em 2007, publicou-se a instrução normativa $n^{\circ} 001 / 2007$, a qual estabelece critérios específicos para o licenciamento ambiental para novos empreendimentos do setor sucroalcooleiro, dentre os quais, tratando-se diretamente da proteção do solo, pode-se destacar a exigência de apresentação projeto de fertirrigação, assim estabelecida:

Art. $1^{\circ}$ - O licenciamento ambiental para os novos empreendimentos do setor sucroalcooleiro se dará obedecendo aos critérios a seguir:

\section{(...)}

VIII. Apresentar projeto de fertirrigação contemplando, no mínimo: estudo de permeabilidade dos solos, quantidade do efluente a ser aplicado, taxa de aplicação e distância de no mínimo 200 (duzentos) metros das coleções hídricas, contados a partir do limite da área de preservação permanente (Goiás, 2007, grifo nosso).

Tal instrução normativa determina ainda que "O plantio de cana de açúcar deverá ser feito apenas em áreas já antropizadas” (Goiás, 2007, p. 5). Dessa imposição legal decorre, por consequência lógica, a vedação ao plantio da cana em terras até àquela época não exploradas pela ação humana, ou seja, áreas de vegetação natural. Em contrapartida não se atenta à capacidade de uso da terra, eis que o fato de ser uma área antrópica não significa dizer que aquele espaço está apto a receber qualquer tipo de cultura.

Desse modo, destacadas as leis em vigor no período em estudo (2004 a 2010), buscamos analisar a relação entre a expansão do cultivo da cana-de-açúcar na microrregião de Quirinópolis e os limites legais estabelecidos, atendo-se ao avanço territorial do cultivo e ao uso do efetivo da terra, não considerando aqui as exigências documentais para a exploração legal dessa atividade (Estudo de Impacto Ambiental - EIA e Relatório de Impacto Ambiental - RIMA).

\section{Capacidade e uso efetivo da terra na microrregião de Quirinópolis - GO $x$ Legislação de proteção do solo}

O planeta Terra é coberto por dois principais elementos: terra e água. O Instituto Brasileiro de Geografia e Estatística - IBGE define as áreas cobertas pela terra em dois grupos: áreas antrópicas e áreas naturais, sendo que cada um desses grupos se divide em dois subgrupos: as áreas antrópicas se subdividem em agrícolas e não agrícolas e as áreas naturais em florestal e campestre. As áreas cobertas por água, por sua vez, se dividem em corpos d'água continentais e corpos d'água costeiros (IBGE, 2006).

As expressões "uso da terra" e "capacidade de uso da terra" não são sinônimas, pelo contrário, por muitas vezes existe entre estas uma incompatibilidade. Entende-se por "uso da terra" a maneira com que a área territorial é utilizada pelo homem, enquanto que a "capacidade de uso da terra" guarda relação com a aptidão do solo e limites naturais para o uso (Silva \& Castro, 2011).

Segundo Lepsch et al. (1991), cada solo possui uma limitação natural a ser respeitada, uma vez que quando utilizado além do limite máximo pode resultar em danos ambientais. Nesse sentido, nem todo solo está apto a receber qualquer tipo de 
cultura indiscriminadamente, por essa razão, deve-se considerar as características do solo e a sua capacidade de uso para identificar a possibilidade de exploração adequada da terra por meio da atividade agrícola, evitando, assim, a instalação de processos de degradação.

Conforme identificado por Silva \& Castro (2011), até 2004, quando ainda não havia a entrada da cana-de-açúcar na microrregião de Quirinópolis, as duas principais predominâncias no uso da terra eram, respectivamente, pastagem, ocupando $72,58 \%$ da área da região, e vegetação natural, correspondendo a 15,42\% (Tabela 1). Dessa análise, cabe destacar a discrepância apontada entre o percentual da área ocupada pela pastagem em relação à área de vegetação natural, o que representa um indicador de grande presença de área antropizada já àquela época.

Em 2010 o cultivo da cana-de-açúcar já ocupava $7,23 \%$ da área da microrregião, o que representava 1.160,030 km² (Tabela 2), evidenciando a expressiva expansão da atividade. Identificou-se que, dentre os tipos de uso da terra que reduziram nessas áreas nesse período, a pastagem apresentou uma diminuição de 14,95\%, além das áreas de ve- getação natural, que apresentam um decréscimo de $7,067 \mathrm{~km}^{2}$ em apenas 6 (seis) anos.

Curioso destacar que as áreas de cultura anual não apresentaram decréscimo, pelo contrário, esse tipo de uso saltou de 9,31\% em 2004 para 16,68\% em 2010. Todavia, Silva \& Castro (2011) advertem que a cartografia da cana-de-açúcar revela que essa cultura é inserida em áreas de grãos, ao passo que estes se deslocam para áreas de pastagem, além disso, é usual a plantação de um ciclo de soja nas áreas de pastagens como forma de preparar esse solo para o plantio da cana.

Dessa forma, é incontestável o abrupto avanço da cana-de-açúcar na microrregião, especialmente sobre as áreas antes ocupadas por pastagens e atividade agropecuária. Porém, além dos valores numéricos, deve-se considerar os impactos da expansão da cana nos solos da microrregião, uma vez que a substituição de cultura deve ser desenvolvida em atenção à capacidade de uso da terra, caso contrário, acarreta diretamente na degradação do solo.

Segundo Silva \& Castro (2011), com base no estudo da capacidade de uso das terras desenvolvido por Lepsch et al. (1991), 64,18\% da área da microrregião de Quirinópolis é classificada com uma área

TABELA 1 - Tipo de uso da terra e área ocupada na microrregião de Quirinópolis em 2004.

\begin{tabular}{cccc}
\hline Tipo de uso & Área em ha & Área em km & \% da microrregião \\
\hline Cana-de-açúcar & 0 & 0 & 0 \\
Cultura anual & $149.585,741$ & $1.495,857$ & 9,31 \\
Pivô & 769,441 & 7,694 & 0,05 \\
Pastagem & $1.166 .208,300$ & $11.662,083$ & 72,58 \\
Vegetação & $247.932,100$ & $2.479,321$ & 15,42 \\
Drenagem & $40.465,910$ & 404,659 & 2,52 \\
Área urbana & $1.841,807$ & 18,418 & 0,12 \\
\hline Total & $\mathbf{1 . 6 0 6 . 8 0 3 , 3 0 0}$ & $\mathbf{1 6 . 0 6 8 , 0 3 3}$ & $\mathbf{1 0 0}$ \\
\hline
\end{tabular}

FONTE: Silva \& Castro (2011). 
TABELA 2 - Dados do uso da terra na MRQ em 2010.

\begin{tabular}{|c|c|c|c|}
\hline Tipo de uso & Área em ha & Área em km² & $\%$ da microrregião \\
\hline Cana-de-açúcar & $116.003,007$ & $1.160,030$ & 7,23 \\
\hline Cultura anual & $268.072,572$ & $2.680,725$ & 16,68 \\
\hline Pastagem & $926.003,100$ & $9.260,031$ & 57,63 \\
\hline Vegetação & $247.225,400$ & $2.472,254$ & 15,38 \\
\hline Área urbana & $1.841,807$ & 18,418 & 0,12 \\
\hline & $1.606 .803,300$ & $16.068,033$ & 100 \\
\hline
\end{tabular}

FONTE: Silva \& Castro (2011).

de capacidade de uso B VI, ou seja, terras cultiváveis em casos especiais por cultura permanente, adaptada para pastagem ou reflorestamento, com problemas especiais de conservação. Dessa forma, a maior parte da área da microrregião não possui capacidade de uso para o plantio de cana-de-açúcar, principalmente pela necessidade de uso massivo de maquinários agrícolas (Silva \& Castro, 2011).

Quando comparada a capacidade de uso com o uso efetivo das terras, obtém-se discrepância entre eles, ou seja, o quanto o uso é superior ou não corresponde à capacidade daquele solo. No caso da Microrregião de Quirinópolis, antes da entrada da cana (2004) era perceptível uma baixa discrepância de uso, referindo-se a $87,34 \%$ da área total, já a discrepância em níveis muito alto e alto totalizava 9,78\% da área. Porém, em 2010 o somatório da discrepância em nível alto e muito alto atingiu $16,16 \%$ da área, estampando a inaptidão do solo da região para o uso intensivo do solo, e com isso a possibilidade de instalação de impactos ambientais.

Os solos da microrregião de Quirinópolis possuem como característica textura média a argilosa, relativa aos Latossolos Vermelhos com alto potencial de compactação, quando utilizados além de sua capacidade. Considerando que os processos utilizados para o cultivo e manejo da cana-de-açúcar são altamente tecnificados, com uso de grandes maquinários agrícolas que causam pressão no solo, a instalação do impacto ambiental nesses solos é previsível (Silva \& Castro, 2011)

Lamentavelmente, percebe-se por meio da legislação federal e estadual que, em termos legais, não há uma preocupação pontual com relação às várias possibilidades de degradação do solo decorrentes das atividades agrícolas. Em termos de compactação do solo, como se viu, a legislação sequer faz menção à ocorrência desse impacto ambiental. Assim, questiona-se a possibilidade de se proteger um recurso quando a própria legislação nacional não o considera em suas particularidades.

\section{Conclusões}

Com base na discrepância entre o uso efetivo e a capacidade de uso da terra, intensificada pelo avanço da cana-de-açúcar na microrregião de Quirinópolis, percebe-se o potencial de degradação do solo decorrente do uso terra em desconformidade com a sua aptidão. Como visto, as características 
dos solos da microrregião não são favoráveis ao manejo tecnificado da cana-de-açúcar, isso por apresentarem potencial de compactação alto ou muito alto.

Considerando os dados apurados quanto ao avanço da cana, especialmente em áreas de pastagem, é possível perceber que, em aspectos legais, especialmente no que regula a instrução normativa nº01/2007, as áreas ocupadas pela cana-de-açúcar, em sua maioria, eram áreas antropizadas, sendo possível, portanto, o requerimento do licenciamento ambiental desta atividade de acordo com a imposição legal inserida na instrução normativa.

Porém, como já visto, a existência de área antropizada não significa que por já ter ocorrido a alteração da paisagem natural pela ação do homem qualquer outra forma de uso da terra a partir de então seja conveniente, quando consideramos a conservação dos recursos naturais, em especial o solo. Muito embora já tendo ocorrido a intervenção no meio natural, a degradação do solo pode-se agravar a depender da nova forma de uso que será destinada à área.

No presente caso, as áreas de pastagem substituídas pela entrada da cana já eram antropizadas, porém verificou-se nitidamente a incompatibilidade da atividade agrícola em relação à capacidade de uso da terra na microrregião de Quirinópolis. Dessa forma, a previsão contida na Instrução normativa $n^{\circ}$ 001/2007 não assegura a proteção do solo, isso porque desconsidera a capacidade de uso da terra, atendo-se a analisar se a área é antrópica ou natural.

No que tange ao avanço da cana em áreas de vegetação nativa, é notório o descumprimento legal, uma vez que a Instrução Normativa $n^{0}$ 001/2007 estabelece, taxativamente, que deverá ser realizado o cultivo da cana somente em áreas já antropizadas.
A redução da área de vegetação natural evidencia a afronta à imposição legal.

Além disso, caso essa área de vegetação natural estivesse inserida em área rural em que já existisse desmatamento e essa área desmatada tivesse sendo utilizada por atividade em desconformidade com a capacidade do solo, como verificado na microrregião de Quirinópolis, também por força do Código Florestal Brasileiro de 1965 (Lei no 4.771/1965), seria vedada a conversão da vegetação natural em outra forma de uso da terra. Porém, verificou-se por meio dos dados apresentados que, independentemente da existência da legislação federal e estadual proibindo a supressão da vegetação natural, houve a violação desta para o cultivo da cana.

Muito embora a Constituição Federal e o Código Florestal de Goiás de 1995 vinculem a possibilidade de supressão da vegetação nativa para conversão em uso alternativo da terra à apresentação de Estudo de Impacto Ambiental, dificilmente o agente estadual competente por analisar esses estudos considerará os danos acarretados ao solo, especialmente em razão da omissão legal quanto a esse recurso.

Percebe-se, ainda, que a legislação, seja ela federal ou estadual, ao fazer menção ao uso do solo na área rural, em regra, está mais atrelada à proteção da vegetação do que do solo, isso porque, como se viu, o que se regula é a possibilidade de supressão da vegetação e a autorização para o desmatamento. Até mesmo a lei que instituiu os crimes ambientais no país (Lei $n^{\circ}$ 9.605/98) somente faz referência ao solo quando este é consequência de uma ação primária que acarrete a erosão, não tipificando condutas diretamente relacionadas à violação ao solo e sua degradação em razão da discrepância entre a capacidade de uso da terra e o seu uso efetivo. 
A legislação estadual que teria por obrigação constitucional legislar sobre aspectos específicos do solo goiano perpassa pela matéria, porém, não diferente da legislação federal cuja obrigação seria estabelecer regras gerais, não apresenta conteúdo que ampare e promova a proteção do solo.

Assim, o que se concluiu é que o solo goiano, embora seja um recurso natural fundamental para a conservação da biodiversidade e vida na Terra, não goza da proteção que lhe é devida. Além disso, as omissões e lacunas na lei acabam por "possibilitar" a ocorrência de situações como a enfrentada na microrregião de Quirinópolis, onde a discrepância entre o uso efetivo e a capacidade de uso da terra, intensificado com a entrada da cana-de-açúcar, compromete a qualidade do solo da região.

\section{Referências}

Ab'sáber, A. N. Do Código Florestal para o Código da Biodiversidade. Biota Neotropica, 10(4), 2010. Disponível: http://www.biotaneotropica.org.br/v10n4/en/abstract?point-of view+bn01210042010

Bertoni, J.; Lombardi Neto, F. Conservação do solo. São Paulo: Ícone, 2005.

Brasil. Lei $n^{\circ} 4.771$ de 15 de setembro de 1965. Institui o novo código Florestal. Brasília: DOU de 15/09/1965.

Brasil. Lei $n^{\circ}$ 6.938, de 31 de agosto de 1981. Dispõe sobre a Política Nacional do Meio Ambiente, seus fins e mecanismos de formulação e aplicação, e dá outras providências. Brasília: DOU de 02/09/1981.

Brasil. Lei $n^{\circ} 7.876$, de 13 de novembro de 1989. Institui o Dia Nacional da Conservação do Solo a ser comemorado, em todo o País, no dia 15 de abril de cada ano. Brasília: DOU de 15/11/1989.

Brasil. Lei no 8.171/1991, de 17 de janeiro de 1991. Dispõe sobre a política agrícola. Brasília: DOU de 18/01/1991.
Brasil. Lei $n^{\circ}$ 9.605, de 12 de fevereiro de 1998. Dispõe sobre as sanções penais e administrativas derivadas de condutas e atividades lesivas ao meio ambiente, e dá outras providências. Brasília: DOU de 13/02/1998.

Brasil. Lei $n^{\circ} 12.651$, de 25 de maio de 2012. Dispõe sobre a proteção da vegetação nativa; altera as Leis $\mathrm{n}^{\text {os }} 6.938$, de 31 de agosto de 1981, 9.393, de 19 de dezembro de 1996, e 11.428, de 22 de dezembro de 2006; revoga as Leis $n^{\text {os }} 4.771$, de 15 de setembro de 1965, e 7.754, de 14 de abril de 1989, e a Medida Provisória n ${ }^{\circ}$ 2.166-67, de 24 de agosto de 2001; e dá outras providências. Brasília: DOU de 28/05/2012.

Brasil. Constituição Federal da República do Brasil de 1988. Texto constitucional promulgado em 5 de outubro de 1988, com as alterações determinadas pelas Emendas Constitucionais de Revisão nos 1 a 6/94, pelas Emendas Constitucionais nos 1/92 a 85/2015 e pelo Decreto Legislativo no 186/2008. - Brasília: Senado Federal, Coordenação de Edições Técnicas, 2015.

Castro, S. S. de et al. A expansão da cana-de-açúcar no Cerrado e no Estado de Goias: elementos para uma analise espacial do processo. Boletim Goiano de Geografia, 30(1), 171-191, 2010.

Castro, S. S. de et al. Estudo da expansão da cana-de-açúcar no Estado de Goiás: subsídios para uma avaliação do potencial de impactos ambientais. In: FÓRUM DE CIÊNCIA \& TECNOLOGIA NO CERRADO, 2., 2007, Goiânia. Anais... Goiânia: SBPC, 2007. p. 9-17.

Freire, O. Solos das regiões tropicais. Botucatu: FEPAF, 2006.

Goiás. Constituição do Estado de Goiás de 05 de outubro de 1989. Goiânia: 05/10/1989.

Goiás. Lei $n^{\circ} 12.596$, de 14 de março de 1995. Institui a Política Florestal do Estado de Goiás e dá outras providências. Goiânia: DO de 14/03/1995.

Goiás. Lei $n^{\circ} 18.104$, de 18 de julho de 2013. Dispõe sobre a proteção da vegetação nativa, institui a nova Política Florestal do Estado de Goiás e dá outras providências. Goiânia: DO de 23/07/2013.

Goiás. Instrução Normativa $n^{\circ}$ 001/2007. Goiânia: DO de 21/06/2007. Disponível em:<http://www.mp.go.gov.br/ 
nat_sucroalcooleiro/Documentos/lic_ambiental/02.pdf $>$. Acesso em: 14 jan. 2019.

IBGE - Instituto Brasileiro de Geografia e Estatística. Manual Técnico de Uso da Terra. 2 ed. Rio de Janeiro: IBGE, 2006.

Lepsch, I. F. et al. Manual para levantamento utilitário do meio físico e classificação das terras no sistema de capacidade de uso. Campinas: Sociedade Brasileira de Ciência do Solo, 1991.

Manzzato, C. V. (Org.). et al. Zoneamento agroecológico da cana-de-açucar. Rio de Janeiro: Embrapa Solos, 2009. 55p.

Miziara, F. Expansão da Lavoura de Cana em Goiás e Impactos Ambientais. In: XIV CONGRESSO BRASILEIRO DE SOCIOLOGIA, 2009, Rio de Janeiro. Artigo completo. Rio de Janeiro, 2009.

Pereira, L. C. et al. Aptidão agrícola como subsídio agroecológico das terras. Embrapa, Jaguariúna, 2006.

Pessôa, V. L. S.; Inocêncio, M. E. O PROCEDER (re) visitado: as engrenagens da territorialização do capital no Cerrado. Revista de Geografia Agrária, Edição especial do XXVI ENGA - 2012, 1-22, 2014.

Resende, M. et al. Pedologia: bases para distinção de ambientes. Lavras: Editora da UFLA, 2007.
Rocha, M. D.; Maciel, D. P. O Desenvolvimento de Goiás e o POLOCENTRO. In: IV Simpósio Nacional de Ciência e Meio Ambiente. 2013, Anápolis. Anais...ANÁPOLIS: UniEvangélica, 2013.

Santos, F. C. V. DOS. et al. Qualidade física do solo em ambiente de sistemas dinâmicos. 2012.

Sartori, R. C. O pensamento ambiental sistêmico: uma análise científica da ESALQ/USP, Dissertação (Mestrado) Universidade de São Paulo, Escola Superior de Agricultura Luiz de Queiroz, 2005, $109 \mathrm{f}$.

Silva, A. A.; Castro, S. S. de. Dinâmica de uso da terra e expansão da cana-de-açúcar entre os anos de 2004 a 2010, na microrregião de Quirinópolis, Goiás. In: Pietrafesa, J. P.; Silva, S. D. e. (Org.). Transformações no cerrado: processo, consumo e natureza. 1ed. Goiânia: Ed. da PUC Goiás, 2011, v., p. 155-188.

Silva, A. A.; Miziara, F. Avanço do setor sucroalcooleiro e expansão da fronteira agrícola em Goiás. Pesquisa Agropecuária Tropical, 41(3), 399-407, 2011. 